\title{
Effect of Different Sintering Cycles on the Surface Hardness of Full Contour Monolithic Zirconia - An In Vitro Comparative Study
}

\author{
Sanath Kumar Shetty ${ }^{1}$, Feba Maria Varghese ${ }^{2}$, Mohammed Zahid ${ }^{3}$, Savitha Dandekeri ${ }^{4}$, Fowzaan Feroz ${ }^{5}$ \\ 1,2,3,4,5 Department of Prosthodontics, Crown and Bridge, Yenepoya Dental College, Yenepoya University, \\ University Road, Deralakatte, Mangalore, Karnataka, India.
}

\section{ABSTRACT}

\section{BACKGROUND}

This in-vitro study was conducted to compare the effect of different sintering cycles on the surface hardness of full contour monolithic Zirconia.

\section{METHODS}

In this in-vitro study, a total of 28 bar shaped Zirconia samples of final dimensions 20 x 4 x 2 mm were fabricated using Amann Girrbach CAD - CAM unit. These samples were randomly allocated into four groups with 7 samples in each group namely, Group 1, 2, 3 and 4 (Group 1: Long sintering cycle, Group 2: Intermediate sintering cycle, Group 3: Short sintering cycle, Group 4: Ultra-short sintering cycle) and sintered under the respective sintering cycles. The Ceramill ${ }^{\circledR}$ Therm sintering furnace provided 3 sintering cycles ranging from the longest Group - 1 (19 hours), to the short sintering cycle Group - 3 (8 hours), with an intermediate sintering cycle Group - 2 (15hours). The Zircom sintering furnace provided an ultra-short sintering cycle Group - 4 ( 2 hours). The testing of surface hardness was performed using TECSOL hardness tester. Statistical analysis of the collected data was performed by one - way ANOVA using SPSS software. Multiple comparison was done using post-hoc Tukey's test.

\section{RESULTS}

One - way ANOVA showed statistically significant difference in the surface hardness of different samples $(\mathrm{P}<0.05)$. The highest mean hardness was observed in Group 3 with $2713.757 \pm 233.89 \mathrm{VHN}$, followed by Group 2 with $2595.714 \pm 62.35$ VHN, followed by Group 4 with $2518.600 \pm 103.65$ VHN and Group 1 with the least, $1734.300 \pm 460.20 \mathrm{VHN}$.

\section{CONCLUSIONS}

The surface hardness of full contour monolithic Zirconia was influenced to some extent by various sintering cycles. The longest sintering cycle showed the least surface hardness whereas, the short sintering cycle showed the highest surface hardness. Also the ultra-short sintering cycle of 2 hours exhibited surface hardness comparable to the other sintering cycles with longer duration, making it a viable alternative to the conventional sintering cycles.

\section{KEY WORDS}

Monolithic Zirconia, CAD - CAM, Sintering, Hardness
Corresponding Author: Dr. Feba Maria Varghese, Room No. 302, A Block, Siliconia Apartments, Near Kuthar, Deralakkatte, Mangalore, Karnataka, India. E-mail: dr.febamariav.93@gmail.com

DOI: $10.14260 / \mathrm{jemds} / 2021 / 427$

How to Cite This Article: Shetty SK, Varghese FM, Zahid M, et al.. Effect of different sintering cycles on the surface hardness of full contour monolithic zirconia - an in vitro comparative study. $J$ Evolution Med Dent Sci 2021;10(28):20892093, DOI: 10.14260/jemds/2021/427

Submission 07-03-2021, Peer Review 12-05-2021, Acceptance 18-05-2021, Published 12-07-2021.

Copyright (C) 2021 Sanath Kumar Shetty et al.. This is an open access article distributed under Creative Commons Attribution License [Attribution 4.0 International (CC BY 4.0)] 


\section{BACKGROUND}

In the current period in dentistry, several materials are available to replace missing single and multiple teeth. This evolution is evident from the usage of metals alone, to the present day ceramics, which have proved to be more durable, functional and aesthetic. ${ }^{1}$ Metal - ceramic restorations have been in use in dentistry for a very long time. Several innovations in the field of metal - ceramic system dominated the dental materials research field for the past many years due to its excellent strength, biocompatibility and aesthetic appeal. However, these restorations being layered or veneered with ceramic over a metallic substructure pose the disadvantage of metal visibility at the gingival margins and even metal allergies in some patients. This has led the research in finding an ideal ceramic substructure or core with comparable strength and properties to that of metal. ${ }^{1}$

The advent of CAD - CAM technology during the mid 1980s brought a leap in the field of dentistry. CAD - CAM technology not only enabled the quick and precise production of prosthetic replacements but also led to various studies especially about new ceramic materials. Among the new ceramic materials, zirconia restorations have become very popular due to their unique mechanical properties as well as optical properties.

Initially, zirconia was also used as a substructure over which a ceramic layer was veneered. However, delamination / chipping of the veneered ceramic was a major drawback the dentists encountered. This led to the development of monolithic zirconia restorations which were fully contoured, more translucent and unveneered. ${ }^{2}$ Every step in the fabrication of zirconia, right from blank fabrication, machining, sintering process, and surface treatments, whether chemical, thermal, or mechanical has to be carefully controlled in order to achieve expected mechanical properties. Of these steps, the sintering process is the most critical step of the ceramic production, which determines the performance of the final product. ${ }^{3}$ When zirconia is subjected to heating, in a controlled environment, for a predetermined time and temperature the material undergoes a process of fusion or sintering. Various sintering cycles have been documented based on manufacturers recommended time, heating temperature, cooling time, etc. Conventional sintering cycles are usually quite time consuming and usually takes around 12 - 18 hours of sintering process in order to achieve desired properties of zirconia.

This process being long and time consuming has encouraged manufacturers to develop speed and high speed sintering cycles that finishes the sintering process in less than 2 hours, with optimal properties for the material, thereby providing a possible alternative to the conventional sintering cycles. However, it became evident that a lot of issues with zirconia restorations were related to the sintering cycles, such as the crystalline content and grain growth of the material which in turn affected its mechanical properties. ${ }^{3}$ The effect of different sintering cycles on the mechanical properties like surface hardness of full contour monolithic zirconia has not been well documented in literature.

Therefore, this in-vitro study was undertaken to compare the effect of different sintering cycles on the surface hardness of full contour monolithic zirconia.

\section{Objectives}

1. To evaluate the surface hardness of full contour monolithic zirconia sintered by heating the material from room temperature to $900^{\circ} \mathrm{C}$ at a rise of $8^{\circ} \mathrm{C} /$ minute and held at $900^{\circ} \mathrm{C}$ for 30 minutes, again followed by a rise to $1450^{\circ} \mathrm{C}$ with a heating rate of $8^{\circ} \mathrm{C} /$ minute and held for 2 hours, followed by a defined cooling rate of $5^{\circ} \mathrm{C} /$ minute till $900^{\circ} \mathrm{C}$ temperature was reached, again followed by a gradual cooling time for 12 hours till a temperature of $200^{\circ} \mathrm{C}$ was reached.

2. To evaluate the surface hardness of full contour monolithic zirconia sintered by heating the material from room temperature to $1450^{\circ} \mathrm{C}$ at a rise of $8^{\circ} \mathrm{C} /$ minute and held at $1450^{\circ} \mathrm{C}$ for 2 hours followed by a gradual cooling time for 10 hours till $200^{\circ} \mathrm{C}$ temperature was reached.

3. To evaluate the surface hardness of full contour monolithic zirconia sintered by heating the material from room temperature to $1450^{\circ} \mathrm{C}$ at a rise of $12^{\circ} \mathrm{C} /$ minute and held at $1450^{\circ} \mathrm{C}$ for 1 hour followed by a gradual cooling time for 6 hours till $200^{\circ} \mathrm{C}$ temperature was reached.

4. To evaluate the surface hardness of full contour monolithic zirconia sintered by heating the material from room temperature to $200^{\circ} \mathrm{C}$ in the first 5 minutes, followed by a rise up to $600^{\circ} \mathrm{C}$ in the following 10 minutes, then $990^{\circ} \mathrm{C}$ in the following 10 minutes, followed by rise up to $1200^{\circ} \mathrm{C}$ in the next 15 minutes, followed by rise up to $1450^{\circ} \mathrm{C}$ in the next 20 minutes, followed by a holding time of 30 minutes at this point, slowly cooling down till $800^{\circ} \mathrm{C}$ in the next 15 minutes and finally cooling down to $200^{\circ} \mathrm{C}$ in the following 15 minutes finishing the entire sintering cycle in a span of 2 hours.

5. To compare the surface hardness of full contour monolithic zirconia bars after sintering with the different sintering cycles.

\section{METHODS}

This is an in-vitro study conducted from July 2020 to November 2020. 28 Zirconia Bars of final dimensions $20 \mathrm{x} 4 \mathrm{x}$ $2 \mathrm{~mm}$ (Fig 1) were fabricated using Amann Girrbach Ceramill@ CAD / CAM Material - ZOLID HT+. These specimens were divided into four groups with 7 specimens in each group. Four different sintering cycles were used in each group as follows: -

\section{Group 1}

Full contour monolithic Zirconia bars of $20 \times 4 \times 2 \mathrm{~mm}$ were sintered by heating the material from room temperature to $1450^{\circ} \mathrm{C}$ at a rise of $8^{\circ} \mathrm{C} /$ minute and held at $1450^{\circ} \mathrm{C}$ for 2 hours followed by a defined cooling rate of $125^{\circ} \mathrm{C}$ per hour for 10 hours till $200^{\circ} \mathrm{C}$ temperature was reached.

\section{Group 2}

Full contour monolithic Zirconia bars of $20 \times 4 \times 2 \mathrm{~mm}$ were sintered by heating the material from room temperature to $1450^{\circ} \mathrm{C}$ at a rise of $12^{\circ} \mathrm{C} /$ minute and held at $1450^{\circ} \mathrm{C}$ for 1 hour followed by a defined cooling rate of $208^{\circ} \mathrm{C}$ per hour for 6 hours till $200^{\circ} \mathrm{C}$ temperature was reached. 


\section{Group 3}

Full contour monolithic Zirconia bars of $20 \times 4 \times 2 \mathrm{~mm}$ were sintered by heating the material from room temperature to $900^{\circ} \mathrm{C}$ at a rise of $8^{\circ} \mathrm{C} /$ minute and held at $900^{\circ} \mathrm{C}$ for 30 minutes, again followed by a rise to $1450^{\circ} \mathrm{C}$ with a heating rate of $8^{\circ} \mathrm{C} /$ minute and held for 2 hours, followed by a defined cooling rate of $5^{\circ} \mathrm{C} /$ minute till $900^{\circ} \mathrm{C}$ temperature was reached, again followed by a defined cooling rate of $58^{\circ} \mathrm{C} /$ hour till a temperature of $200^{\circ} \mathrm{C}$ was reached.

\section{Group 4}

Full contour monolithic Zirconia bars of $20 \times 4 \times 2 \mathrm{~mm}$ were sintered by heating the material from room temperature to $990^{\circ} \mathrm{C}$ at a rise of $60^{\circ} \mathrm{C} /$ minute followed by a rise to $1450^{\circ} \mathrm{C}$ with a heating rate of $13^{\circ} \mathrm{C} /$ minute and held for 1 hour, followed by a cooling time of 2 hours till a temperature of $200^{\circ} \mathrm{C}$ was reached.

The Ceramill ${ }^{\circledR}$ Therm (Amann Girrbach) sintering furnace provided 3 sintering cycles ranging from the longest Group - 1 (19 hours), to the short sintering cycle Group - 3 (8 hours), with an intermediate sintering cycle Group - 2 (15hours).

The Zircom (KDF U.S., Inc.) sintering furnace provided an ultra - short sintering cycle Group - 4 (2 hours).

All the sintered samples were polished using Polishing kit (Ceramill polish lab kit) and glazed using Glaze paste (IPS E. Max Ceram Ivoclar Vivadent) at a final temperature of $790^{\circ} \mathrm{C}$ for seven to eight minutes in Programat P310 (Ivoclar Vivadent) ceramic furnace.

Bars from each group sintered under 4 different sintering cycles were loaded in TECSOL hardness tester (Fig 2) for testing hardness. A load of $9.81 \mathrm{~N}$ was applied on three different points on the samples and surface hardness was calculated.

\section{Statistical Analysis}

Statistical analysis was done by using SPSS software. One - way ANOVA test was performed to compare the four groups for surface hardness which revealed significant difference in the mean $(\mathrm{P}<0.05)$ Tukey's post - hoc test was performed for multiple comparisons, as significant differences among groups were observed (Table-2)

\section{RESULTS}

The present study compared the surface hardness of full contour monolithic Zirconia bars after sintering with four different sintering cycles. The mean surface hardness and standard deviation were calculated for each group. The surface hardness results (Mean + Standard deviation) for all the four groups are summarized in Table 1.

\begin{tabular}{|c|c|c|c|}
\hline & $\begin{array}{l}\text { Mean (Standard } \\
\text { Deviation) }\end{array}$ & P Value & $95 \%$ Interval \\
\hline Group 1 ( Long) & $1734.300(460.20)$ & & 1308. \\
\hline $\begin{array}{c}\text { Group } 2( \\
\text { intermediate) }\end{array}$ & 2595.714 (62.35) & & 2538.044 to 2653.38 \\
\hline Group 3 ( short) & 2713 & 0.000 & .07 \\
\hline Group 4 ( ultra short) & $2518.600(103.65)$ & & 2422.73 to 2614.46 \\
\hline \multicolumn{4}{|c|}{$\begin{array}{l}\text { Table 1. Comparison of Surface Hardness of Full Contour Monolithic } \\
\text { Zirconia Sintered Under Different Cycles between the Groups }\end{array}$} \\
\hline
\end{tabular}

Highest mean surface hardness was recorded in Group 3 (Short sintering cycle) with 2713.757 VHN, followed by Group 2 (Intermediate sintering cycle) with $2595.714 \mathrm{VHN}$, then Group 4 (Ultra - Short sintering cycle) with 2518.600 VHN and Group 1 (long sintering cycle) with 1734.300 VHN as described in Table 1.

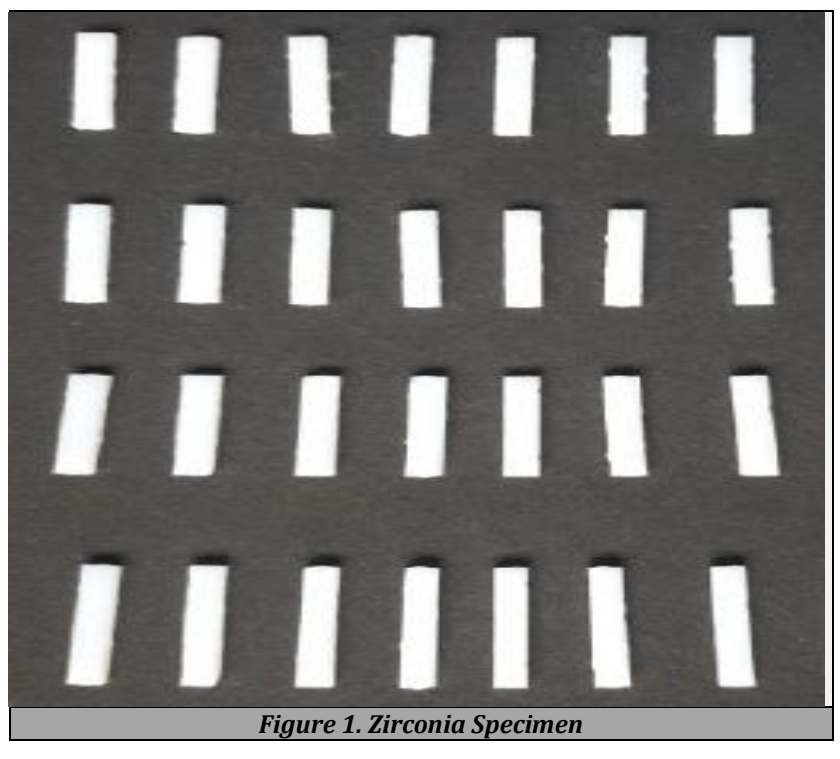

\begin{tabular}{|c|c|c|c|}
\hline Group & Comparison & $\begin{array}{c}P \\
\text { Value }\end{array}$ & $\begin{array}{c}95 \% \text { Confidence } \\
\text { Interval }\end{array}$ \\
\hline \multirow[t]{3}{*}{ Group 1 ( Long) } & $\begin{array}{c}\text { Group 2 } \\
\text { (Intermediate) }\end{array}$ & 0.000 & 470.50 to 1252.32 \\
\hline & $\begin{array}{c}\text { Group } 3 \text { ( Short } \\
\text { cycle) }\end{array}$ & 0.000 & 588.546 to 1370.369 \\
\hline & $\begin{array}{c}\text { Group } 4 \\
\text { (Ultra-Short cycle) }\end{array}$ & 0.000 & 1175.212 to 393.388 \\
\hline \multirow[t]{2}{*}{$\begin{array}{c}\text { Group 2 } \\
\text { (Intermediate) }\end{array}$} & Group 3 ( Short) & 0.838 & 508.94 to 272.86 \\
\hline & $\begin{array}{l}\text { Group } 4 \text { (Ultra - } \\
\text { Short cycle) }\end{array}$ & 0.947 & 313.79 to 468.02 \\
\hline $\begin{array}{c}\text { Group } 3 \\
\text { (Short cycle) }\end{array}$ & $\begin{array}{c}\text { Group } 4 \text { Ultra - Short } \\
\text { cycle }\end{array}$ & 0.525 & 195.754 to 586.069 \\
\hline \multicolumn{4}{|c|}{$\begin{array}{l}\text { Table 2. Comparison of Surface Hardness of Full } \\
\text { Contour Monolithic Zirconia Sintered Under } \\
\text { Different Cycles within the Groups }\end{array}$} \\
\hline
\end{tabular}

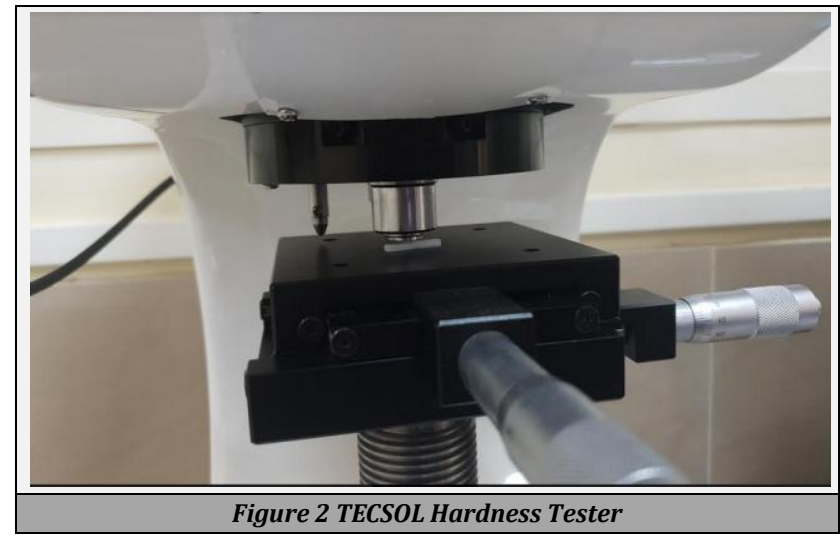

DISCUSSION

In this study, the highest hardness was observed with the short sintering cycle group (i.e group 3) with 2713.757 VHN. The reason for this slight increase in VHN for Group 3 compared to Group 2 (Intermediate cycle) and Group 4 (Ultra - short sintering cycle) could be attributed to the existence of 
monoclinic phase transformation on the surface, even though this comparison was not statistically significant. This result was in accordance to studies conducted by Hjerppe et al. who performed microhardness test on zirconia samples with different holding times ( 3 hours and 1 hour 40 minutes respectively) wherein no statistically significant difference was observed. ${ }^{4}$ This result is also in accordance with the study by Ebeid et al. and Chien et al. who conducted similar hardness tests on Zirconia samples. ${ }^{5}$

An interesting observation in this study is that, the mean hardness of Zirconia samples after sintering with the long sintering cycle with a total span of 19.31 hours (Group 1) was the least (1734.300 VHN) when compared to the rest of the sintering cycles. This sintering cycle also had the longest holding time of 2 hours and 30 minutes in total where the samples were held for 30 minutes at a temperature of $900^{\circ} \mathrm{C}$, followed by a constant temperature rise of $8^{\circ} \mathrm{C}$ per minute up to $1450^{\circ} \mathrm{C}$ and held again for another 2 hours. The reason for the least hardness observed in this group despite being sintered for the longest time could be attributed to the defective integration of Zirconia crystals at the grain boundary in this group, where the Zirconia specimens were initially held for 30 minutes at a temperature of $900^{\circ} \mathrm{C}$, in spite of the fact that the specimens were further sintered to a temperature of $1450{ }^{\circ} \mathrm{C}$ and held again for another 2 hours. Another reason could be attributed to the possible presence of monoclinic phase which has a lower atomic density than the tetragonal phase. Therefore, the reason for the least hardness in Group 1 despite being the longest sintering cycle could be because of the defective integration of Zirconia crystals at the grain boundary leading to the formation of immature crystal structures during the initial short holding time of 30 minutes at $900^{\circ} \mathrm{C}$, which could lead to crack formation. However this result, is not in accordance with the results of the study conducted by Hjerppe et al. who found no significant difference in the surface hardness of Zirconia discs sintered under different conditions. ${ }^{4}$ This also contradicts the results of the study by Cottom et al. who reported that hardness of zirconia ceramics was unrelated to grain size. ${ }^{6}$ Several studies have reported that low temperature degradation (LTD) and excessive $\mathrm{t}-\mathrm{m}$ phase transformation decreased Zirconia micro - hardness.

With the ultra-short sintering cycle group (i.e. Group 4), the entire cycle was for 2 hours with a holding time of 30 minutes at $1450^{\circ} \mathrm{C}$. This group of samples showed a surface hardness of $2518.600 \mathrm{VHN}$, which was at par with all the other conventional sintering cycles. Consistent with the present study, Ebeid et al. and Hjerppe et al. have also reported that no phase transformation occurs on changing the sintering temperature and holding times and that using shorter sintering cycles does not adversely affect the mechanical properties of Zirconia.4,5 However, this was not in agreement with the results of the studies by Swain et al. Juntavee et al. and Inokoshi et al. who found that prolonged sintering holding time increases surface hardness and other mechanical properties of Zirconia.7,8,9

As significant difference in the surface hardness is not found between the conventionally sintered groups and the ultra - short sintered group, it can be suggested that the ultra short sintering cycle may be used as an alternative to the much time consuming conventional sintering process for manufacturing crowns or fixed prosthesis using Ceramill Zolid
HT+ material. This is in agreement with previous studies conducted by Kaizer et al. and Harada et al. who conducted similar studies on conventionally sintered and speed sintered Zirconia, where it was revealed that both the groups were similar in density, microstructure and therefore surface hardness. ${ }^{10}$

According to the results obtained in this study, it may be concluded that the ultra - short sintering cycle, that has a total span of 2 hours can provide restorations that have surface hardness that is comparable to the conventional long sintering cycles. Therefore, it may be suggested that the ultra-short sintering cycle may be used to fabricate crowns or long span fixed dental prosthesis using Ceramill Zolid HT+ material, making 'tooth-in-a-day' almost a reality to the patients. Therefore further comprehensive clinical studies are required to evaluate the influence of altering sintering parameters or fabrication methods on the performance of monolithic Zirconia restorations, and also the phase transformation and crack propagation that is happening in the material after being sintered under different sintering cycles.

\section{CONCLUSIONS}

The highest mean surface hardness was observed with the short sintering cycle (Group 3) with 2713.757 VHN, followed by intermediate sintering cycle (Group 2) with 2595.714 VHN, then ultra - short sintering cycle (Group 4) with $2518.600 \mathrm{VHN}$ and lastly, the long sintering cycle (Group 1) with 1734.300 VHN. There is a statistically significant difference between the surface hardness of full contour monolithic Zirconia after sintering under different sintering cycles. The ultra-short sintering cycle may be used as an alternative to the conventional sintering cycles which saves a lot of time, energy and is economical, which brings 'tooth-in-a-day' possible for the patients.

\section{Limitations}

In the present study oral conditions such as saliva, temperature etc. were not simulated which is actually important in a clinical scenario to estimate the clinical potential of the material. Also the in-vitro load applied was static in nature and therefore does not correspond to the dynamic or cyclic masticatory load, which is an important clinical aspect. The study has used only one brand of Zirconia which is another limitation.

Data sharing statement provided by the authors is available with the full text of this article at jemds.com.

Financial or other competing interests: None.

Disclosure forms provided by the authors are available with the full text of this article at jemds.com.

\section{REFERENCES}

[1] Krishna J, Kumar V, Savadi R. Evolution of metal-free ceramics. The Journal of Indian Prosthodontic Society 2009;9(2):70-5 
[2] Brunton P, Smith P, Mccord J, et al.. Procera all-ceramic crowns: a new approach to an old problem? Br Dent J 1999;186(9):430-4.

[3] Hua Z, Zhang B, Chen J, et al.. The effect of sintering temperature on the physical properties and bending strength of zirconia toughened ceramic. Key Engineering Materials 2012;519:273-6.

[4] Hjerppe J, Vallittu P, Fröberg K, et al.. Effect of sintering time on biaxial strength of zirconium dioxide. Dent Mater 2009;25(2):166-71.

[5] Ebeid K, Wille S, Hamdy A, et al.. Effect of changes in sintering parameters on monolithic translucent zirconia. Dent Mater 2014;30(12):e419-24.

[6] Cottom BA, Mayo MJ. Fracture toughness of nanocrystalline ZrO2-3mol \% Y2O3 determined by vicke8rs indentation. Scr Mater 1996;34(5):809-14.
[7] Swain MV. Grain-size dependence of toughness and transformability of $2 \mathrm{~mol} \%$ y-tzp ceramics. J Mater Sci Lett 1986;5:1159-62.

[8] Juntavee N, Attashu S. Effect of different sintering process on flexural strength of translucency monolithic zirconia. J Clin Exp Dent 2018;10(8):821-30.

[9] Inokoshı M, Zhang F, Munck J, et al.. Influence of sintering conditions on low-temperature degradation of dental zirconia. Dent Mater 2014;30(6):669-78.

[10] Kaizer MR, Gierthmuehlen PC, Dos Santos M, et al.. Speed sintering translucent zirconia for chairside one- visit dental restorations: optical, mechanical and wear characteristics. Ceram Int 2017;43(14):10999 -1005. 